\title{
Entrevista a Adriana Puiggrós
}

\author{
Victoria Baraldi
}

Este número de Itinerarios Educativos lo hemos dedicado al análisis del sistema educativo, la educación pública y, vinculada a ello, el derecho a la educación. Nos propusimos recuperar experiencias, ensayos e investigaciones que, sin desconocer las críticas, también pudiesen mostrar la existencia de la escuela como un espacio donde aún es posible pensar en lo común. Nuestra revista siempre incluye una entrevista a un especialista en el tema de la convocatoria. Consideramos que sos una de las personas que más ha estudiado y que más conoce la historia de nuestra educación, por eso nuestro especial interés en poder conversar con vos.

Para iniciar el diálogo, pensé que sería oportuno tomar una frase de uno de tus libros de reciente publicación: Adiós, Sarmiento. Escuela pública, Iglesia y mercado. ${ }^{(1)}$ Es un libro maravilloso por la cantidad de fuentes, la síntesis que se logra, una escritura muy ágil, llena de metáforas para expresar hipótesis...

(1) Puiggrós, A. (2017). Adiós, Sarmiento. Escuela pública, Iglesia y mercado. Buenos Aires: Colihue.

Bueno. Me alegra que te sirva... 
Sí, muchísimo, ya lo pasé para que lo lean. Como te decía, allí, en la tercera parte considero que planteás lo que para mí es el corazón del libro:

«(...) la Iglesia Católica y el Estado nunca concluyeron su batalla por la educación, pero hoy ambos son claramente amenazados por la misma fuerza helada que proviene del mercado, un motivo más para establecer el laicismo en la educación pública y garantizar el cumplimiento y/o establecimiento de leyes nacionales e internacionales que impidan su mercantilización y comercialización» (p. 239).

Para los que aún no lo leyeron, me gustaría que pudieras comentar tus argumentos en función de esto que me parece importante, y grave a la vez, como para estar atentos.

Sí. Quizás sea bueno, justamente para los que no han leído el libro, decirles cuál es el sentido del título, para empezar. Por qué Adiós, Sarmiento (porque muchas veces me preguntan eso, por qué Adiós, Sarmiento). Entonces, yo siempre les digo algo que está al final del libro y es que —en realidad — nosotros le decimos «adiós» al Sarmiento racista pero hay otros que le dicen «adiós» al Sarmiento de la educación común. Hay que comprender la complejidad del pensamiento de Sarmiento. Él representa, de alguna manera, un pacto de la sociedad argentina. Un pacto fundante en donde hubo vencidos y vencedores, si hablamos de unitarios y federales. También habría que decir que antes estuvo la Constitución de 1853 , que es una Constitución Federal pero escrita por los unitarios. Desde ese lugar, Sarmiento a la vez desprecia profundamente al pueblo argentino y latinoamericano, pero - contradictoriamente- considera que es necesario educar al conjunto y que es válido poner el esfuerzo en la construcción de un sistema de educación común. Ese es un pacto de toda la sociedad, un pacto que incluye desde los inmigrantes, los trabajadores urbanos, los trabajadores rurales, hasta llegar a la oligarquía. Y la idea de sostener el sistema educativo, el sistema escolar público, yo diría que dura aproximadamente 100 años.

Acercándome a la tercera parte, que es la que vos me preguntás, si esto que acabo de decir es el comienzo del libro, la tercera es lo contrario: es el derrumbe, la ruptura precisamente del pacto respecto de la existencia de una Nación, la Argentina. Porque a partir de la Constitución de 1853 y de ahí en adelante, más allá de las disputas internas (de clase, regionales, económico-sociales, culturales), lo que se produce es la fundación de una Nación. Cuando hoy leía las últimas novedades acerca de cómo nos estamos aproximando a la dolarización, y cómo hay una disputa en la cual está la Argentina de por medio entre el Fondo Monetario Internacional y el tesoro de los Estados Unidos, acerca de si lo que hay que hacer es volver a la Convertibilidad o acabar con el peso argentino y dolarizar, y todo lo que significaría para la Argentina... Eso me llevó inmediatamente a asociar con lo que se está haciendo con el sistema educativo, porque justamente se está desnacionalizando el sistema a partir de muchos programas y muchas acciones; en donde lo principal son el desfinanciamiento, el abandono, el insistir en que los docentes son innecesarios, que son suplantables por la tecnología. Una serie de acciones que tienden precisamente a terminar con un sistema de educación pública y a romper —entonces-con ese pacto que mencionaba recién. 
Tremendo... Lo otro que te quería preguntar, vinculado a esto, es sobre uno de los conceptos que vos inauguraste: el de alternativas pedagógicas. Es un concepto que nos permite quitarnos esta mirada homogénea de la educación y, a la vez, hacer visibles prácticas, sujetos, instituciones, procesos. En este sentido, icuál es tu mirada acerca de las alternativas pedagógicas hoy en Argentina, a nivel general y a nivel de la formación docente en particular?

Hoy estaba leyendo una declaración de los docentes de Moreno, ${ }^{(2)}$ en particular de un Instituto Superior de Formación Docente, que tuvieron una asamblea y una discusión durante tres horas (recordemos lo que está ocurriendo, ¿no?, en el distrito de Moreno). En esta decidieron negarse a lo que en la ciudad de Buenos Aires se llama continuidad pedagógica y que consiste en decirles «no quieren dar clases en las escuelas rotas, entonces que no haya clases». $\mathrm{O}$ ir avanzando - $-\mathrm{y}$ esta es una hipótesis fuerte-. aprovechar la situación, por parte del gobierno, de ir avanzando con alternativas al trabajo de los docentes. En este caso, están listos para aplicar programas, paquetes de contenidos, para avanzar hacia reemplazar a los docentes por «animadores», «acompañantes», o como los Ilamen.

El documento de los docentes es muy interesante porque ellos avanzan, no se quedan en consignas, sino que avanzan hacia una discusión políticoeducativa $y$, en especial, pedagógica. Entonces dicen «nosotros no vamos a aceptar esto (con relación a esa idea de continuidad pedagógica o educativa) sino que vamos a hacer otra cosa y la vamos a denominar "acompañamiento pedagógico». Entonces, lo que ellos plantean es: vamos a ser guías nosotros para los estudiantes, vamos a dar clases, no se puede dar clases en las escuelas deshechas, vamos a buscar lugares alternativos. Lo que no vamos a hacer es tomar
(2) La entrevista se realizó el día 16 de septiembre. Tres días antes una docente había sido atacada (secuestrada y torturada) por colaborar en la asistencia de un comedor para menores. El jueves $\mathrm{I} 3$ de septiembre ya estaba convocado un paro general de los gremios docentes, $y$ en ese día los docentes de Moreno

\begin{abstract}
marcharon en repudio al atropello cometido contra la maestra. A su vez, el 2 de agosto una docente y un auxiliar habían muerto a causa de una explosión de gas en una escuela de esa localidad. Estos hechos desataron una serie de reclamos por parte de los docentes.
\end{abstract}

exámenes y acreditar, porque lo que no vamos a hacer es legitimar que se dicten clases de cualquier manera, sin tener en cuenta las condiciones mínimas para hacerlo. Por lo tanto, trabajaremos para que los alumnos no pierdan continuidad en sus estudios. A mí me pareció muy interesante; de hecho, lo subí hace un rato a mi página web para que se conociera.

Yo creo que cuando uno habla de alternativas, lo que primero que tiene que hacer es diagnosticar en qué momento político, educativo, económico se está. No es lo mismo hablar de alternativas en un momento en donde hay políticas de crecimiento, políticas sociales, que en una retracción; en donde - en primer lugar - se impone el cuidar lo que se tiene, defender lo que se tiene. En ese sentido, me parece que lo que es interesante es que estos docentes no quedan solamente en una posición 
defensiva, sino que tratan de avanzar en el «qué hacemos en estas circunstancias».

Entonces creo que, yendo a un plano más amplio, las alternativas que se piensen tienen que tener muy en cuenta el avance de la tecnología y el poder inmenso de las grandes corporaciones. Las cinco más grandes: Apple, Google, Microsoft, Netflix, etc., que realmente están dominando el mercado educativo junto con Pearson, todas ellas, están avanzando en ese mercado hablando de la educación en general, no solamente escolar, y no solamente escuela pública. Con escolar digo las escuelas en general, esto es bien importante. Digamos que el avance es para apoderarse del espacio de las escuelas, del espacio escolar, no solamente del espacio público. Aunque este tiene un particular interés para las grandes corporaciones por muchas razones.

Pero, frente a esto, considero que lo que se plantea es por el lado de diseños político-educativos y pedagógicos en donde el docente domine la tecnología y no la tecnología domine al docente. Que no se cierren de ninguna manera los ojos ante los chicos con celulares, ante los vínculos fuertes —que es un vínculo pedagógico- de los chicos con los programas, con el lenguaje digital. Es un aprendizaje increíble el que hacen... El otro día me contaban unos amigos que descubrieron que su hija adolescente hablaba inglés y ellos no lo sabían. Sucede que ante una situación particular ella dijo: "pero si yo hablo inglés». Entonces sí, hablaba inglés, pero lo hacía con su computadora. Esos lenguajes «secretos» que siguen teniendo los chicos, o secretos para nosotros, que estamos fuera de ese mundo, me parece que es algo que los docentes tienen que tener muy pero muy en cuenta para cualquier alternativa.
De todas maneras, me parece que este aspecto de las alternativas pedagógicas que está en pie desde que se creó el sistema educativo, de la educación moderna, o sea, del siglo XIX, es inverso al tipo de vínculo que establece el sistema educativo moderno. Este último es autoritario y es de alguna manera todo lo que plantea Paulo Freire. Es decir, frente a ese vínculo autoritario hay una alternativa siempre presente que fue estudiada, verbalizada y propuesta por la Escuela Activa: Montessori, Decroly, el Plan Dalton, John Dewey. Por la enorme cantidad de teóricos de la Escuela Activa que empezaron proponiendo, justamente, una educación en donde el alumno tuviera presencia con su palabra, con sus ideas, con su imaginación, con su creatividad, etc. Esto fue tomado por los socialistas, por los anarquistas en Argentina, y aproximadamente hasta la primera mitad del siglo XX fueron muy fuertes las corrientes internas del sistema escolar, como, por ejemplo, las numerosas revistas que se publicaban y que tienen valor hasta ahora.

Hoy leía el mensaje que me mandaba un docente de Corrientes diciendo que estaba buscando la revista La educación, que dirigía Carlos Vergara, y que no la encontraba en ningún lugar. Es una revista en donde una de las discusiones fuertes que se plantean es, de alguna manera, la idea de la participación de los estudiantes, de los alumnos, en materia de disciplina y de normas. Es lo que mucho después Freire va a teorizar con la idea de la educación dialógica, en términos pedagógicos. Y que, en términos de la organización escolar, se han dado muchísimas experiencias (y tiene que haber muchas más) de lo que uno podría llamar cogobierno. O sea, al menos, cuando uno está pensando en el secundario, está pensando también en los institutos de formación docente y 
en la universidad. Es decir, detrás de la idea de cogobierno ya hay mucho camino recorrido.

Es interesante cuando uno recuerda las clases que daba Hipólito Yrigoyen, que sus alumnos participaban de la clase. Hacía una especie de jurado con las alumnas, muy influido por las ideas de la pedagogía krausista. Estoy hablando de corrientes pedagógicas europeas del siglo XIX. Entonces, realmente me parece que hay mucho para andar y mucho para producir, moviéndose en esa línea histórica y pensando en cómo se puede en la actualidad utilizar la tecnología en función de lo que necesite el alumno, de la transmisión de una cultura democrática.

Sí, es por ello que considero siempre tan importante volver al pasado. No como acumulación de información sino justamente para recuperar esos proyectos que en algunos casos fueron realizados y después se desmontaron, o no pudieron crecer como se lo habían propuesto.

Otra de las preguntas que quería hacerte es con relación al derecho a la educación. La Ley de Educación Nacional, particularmente el artículo 2, sostiene: «educación y conocimiento son un bien público y un derecho personal y social garantizado por el Estado". ¿Cómo valoras vos la incorporación real de este derecho en los últimos años?

Con respecto al derecho a la educación... tenía por acá la Constitución de 1949. Porque la primera cuestión es que he leído que algunos autores plantean que la noción de derecho a la educación aparece recién en los últimos años o después de la dictadura, pero no es así. Es importante el ver que la idea de derecho aparece en el capítulo 3 de la Constitución de 1949: el derecho del trabajador, de la familia, de la ancianidad y de la educación y la cultura. Y en el capítulo del derecho a la educación y la cultura (con excepción del encabezamiento en donde les tiembla la mano en cuanto a colocar taxativamente el papel principal del Estado, porque ponen la familia, ¿no?, hay una cierta concesión a la Iglesia, que después el peronismo va retirar... que en gran parte va a ser la causa de su caída). Pero el resto contiene, desde la autonomía universitaria, un esquema de organización interesantísimo de las universidades, obviamente el rescate de la cultura nacional, la obligatoriedad y gratuidad de la educación, etc. Entonces, todo esto como derechos; está planteada la educación como un derecho, derecho a la educación y a la cultura.

Ahora, es la ley actual, la Ley de Educación Nacional, la que plantea integralmente la educación como un derecho. También debemos tener en cuenta que el derecho a la educación en realidad fue planteado después de la Segunda Guerra Mundial por los organismos internacionales.

El tema es que, dada la globalización, ya no es una discusión solamente nacional, nos lleva a ver cuáles son los grandes escenarios en los que nos movemos. Porque el hecho de que nuestras leyes establezcan el derecho a la educación no es ninguna barrera para quienes consideran que en realidad la educación es una variable del mercado. Es decir, la Organización para el Comercio y Desarrollo Económico (OCDE) y la Organización Mundial del Comercio (OMC) de las cuales somos miembros (somos miembros plenos de la OMC y estamos al borde de ser miembros plenos de la OCDE, en donde ya participamos en gran parte de su actividad), establecen que la educación es un bien transable desde fines de los años 90. Si la educación es un bien transable, la educación no es un derecho, es absolutamente contradictorio lo uno y lo otro. Siendo así, nos encontramos con que no 
hay forma de garantizar desde el Estado nacional y desde ningún lugar de la sociedad a la educación como derecho. La educación pasa a ser propiedad de quien la adquiera, pasa a ser propiedad privada, es decir, pasa de ser un bien público a un bien privado. De esta manera, los conjuntos de normas, más las instituciones y el conjunto del personal (en términos de personal que constituye el sistema escolar), quedan anulados. Simplemente por el cambio de una denominación: no es más un derecho, es un bien transable. Ese es el estado en el que estamos.

Entonces, si podemos parar la soberanía de nuestro peso [moneda argentina]; si ahora uno comienza a ver que no fue una broma el hecho de quitar de los billetes los retratos de los próceres para poner animales o flores; si vamos a perder la soberanía de este peso... te doy un ejemplo, si el dólar se fuera a 100 pesos, un docente que cobra 1000 pasaría a cobrar 500. Es decir, su sueldo, que equivale a 1000 pesos, pasaría a valer 500. Esto ha llevado a una situación de miseria, de destrucción realmente fuerte en donde desaparece el derecho a la educación, yo lo veo en esos términos.

Me parece que hay también, al mismo tiempo, una reacción social importante de defensa del derecho a la educación. Las manifestaciones, las marchas que ha habido la semana pasada y la anterior ${ }^{(3)}$ han sido espectaculares. No hubo marchas de este

(3) Se refiere a la multitudinaria marcha realizada en Bueno Aires, el día 30 de agosto en defensa de la educación pública y de la universidad, y la siguiente marcha realizada el $\mathrm{i} 3$ de septiembre por los principales gremios docentes del país. estilo (es decir, contrarias al gobierno) desde 1958, cuando fue la «laica o libre». Hace muchos años, creo que en el '73, no hubo marchas contrarias al gobierno sino que hubo movimientos de apoyo a las reformas que estaba haciendo el gobierno de Cámpora y después el de Perón. No así el de Isabel Perón, que fue el comienzo de la dictadura. Ahora sí nos encontramos con que hay una reacción de defensa del derecho a la educación.

Qué buena tu respuesta, muy completa. Quisiera hacerte una pregunta, quizá más personal, pero me parecía importante realizártela justamente a vos que tenés una muy extensa trayectoria, que te has desempeñado como docente-investigadora y, a la vez, has ocupado cargos políticos y de gestión de la educación. Entonces, pensando que siempre todo conocimiento es político, desde el hecho ya de la selección de los temas, los problemas, las formas de abordarlos, el sentido que uno le da al conocimiento. $Y$ a la inversa, desde la función política, que siempre se basa sobre conocimientos... [risas] i0 que debería basarse en conocimientos! Sobre algunos supuestos, por esto te decía que es una pregunta un poco más personal: icómo vivenciaste ese vínculo en las distintas funciones? Por otro lado, desde tu punto de vista, ¿cuáles son para vos tus principales legados, tus principales producciones?

En cada cargo, yo al menos aprendí, y lo más importante es que siempre trabajé con un equipo. Nunca tuve un equipo improvisado, fueron muchos años de trabajar con equipos renovados (con algunos estoy trabajando hace 30 o 40 años, pero con otros no). Llevo un trabajo previo con muchos de ellos, y cada equipo, en cada función fue un lugar de aprendizaje para los que trabajaban conmigo y para mí. A mí me parece que el estar abierto al aprendizaje es algo muy importante para 
un funcionario. Hablamos de los funcionarios que honestamente llegan a un lugar en el cual no saben cómo les va a ir. No es fácil estar en un lugar de gestión, sea cual fuera la jerarquía, es muy difícil, no solamente la responsabilidad sino el tener mandos sobre las personas. Es algo muy complejo el saber que hay hechos importantes que dependen de lo que uno haga o decida.

Yo tuve la suerte de trabajar en el equipo de Felipe Solá, en la provincia de Buenos Aires, del cual me voy a acordar toda la vida porque era un equipo «de lujo» el que tenía. Por ejemplo, Arslanian era el ministro de Seguridad. Trabajar con Solá fue muy bueno porque es una persona muy inteligente que te deja hacer. Es un gran lector, muy culto. Es decir, no es que yo esté de acuerdo siempre en todo lo que él plantea, pero mi experiencia fue muy pero muy buena.

Después en la Cámara, como diputada, fue complicado. En la época de la Alianza tuve algunas diferencias, algunas veces en contra... En los dos primeros años de esa época fue el menemismo, o sea que estar en la oposición es fácil. Después estuve el otro año y medio durante el gobierno de De La Rúa, y después estuve en la Secretaría de Ciencia y Técnica. Allí hicimos cambios junto con los investigadores (algún día lo voy a escribir a eso, porque tengo muchas cosas escritas y mucho material). Para darte un ejemplo, un ejemplo límite, el día 19 de diciembre de 2001, fuimos con dos asesores, dos colaboradores, dos investigadores, a la computadora central y traspasamos todos los fondos que se podían traspasar a proyectos del noreste argentino que vinculaban a investigadores con universitarios y con pequeños empresarios, con PyMEs. Este tipo de programas, durante el tiempo que estuve (que fue un año más o menos), fue muy fuerte. Mi programa Redes, que después apareció como una novedad, en realidad era un programa que ya se había empezado cuando era Caputo secretario de Ciencia y Técnica, pero era muy débil; entonces durante mi gestión se puso en marcha, se empezaron a repatriar científicos. De hecho, yo estuve en París y en otros países de Europa en reuniones con muchos científicos argentinos conversando sobre su repatriación. Después cayó el gobierno, etcétera.

Y luego, durante el gobierno kirchnerista, fui diputada con Cristina; quien me volvió a ofrecer el lugar en la lista en el siguiente mandato, y yo acepté. Sin embargo, quien me llamó cuando terminó el gobierno de Solá en 2007 fue Néstor, para que integrara la lista del Frente para la Victoria. Ahí fueron ocho años de una experiencia muy fuerte. Yo, durante seis, fui presidenta de la Comisión de Educación. Allí se hicieron muchas cosas, se trabajó - por supuesto- en equipo, no solo con los pedagogos y algunos economistas, sino también con otros diputados y con asesores de diputados. Esa fue una experiencia muy importante, esto es lo que te puedo decir respecto de la gestión. 
La última pregunta es abierta, por si querés agregar algo vos en especial para una revista que procura abordar problemas educativos y que es leída por docentes, egresados, estudiantes...

Yo creo que más o menos está todo, pese a que es un momento en donde hace falta que todos pongamos un esfuerzo. Que haya una revista que aborde problemas educativos, como ustedes, y que abra el debate, me parece que es un gran aporte. Así que muchísimas gracias por la entrevista.

\section{Muchas gracias a vos por tu tiempo.}

\section{Acerca del entrevistado}

Adriana Puiggrós es profesora en Ciencias de la Educación egresada de la Universidad de Buenos Aires y doctora en Educación por la Universidad Autónoma de México. Fue diputada nacional (1997-2001) y (2007-2015) y directora general de Cultura y Educación de la Provincia de Buenos Aires (2005-2007). En la década del '80, fundó el Proyecto Alternativas Pedagógicas y Prospectiva para la Educación en América Latina (APPEAL). Es autora de más de veinte libros y coautora de decenas. Se destaca su producción en el campo de la Historia de la Educación, en especial la colección «Historia de la Educación en la Argentina» (8 tomos), publicada por Galerna en Buenos Aires en el año 1997. Otra de sus obras son: Imperialismo y educación en América Latina (1980), América Latina: Crisis y Prospectivas de la Educación (1990), Volver a Educar. El desafío de la enseñanza argentina a finales del siglo XX (1995), Qué pasó en la educación argentina. De la conquista al menemismo (1996), El lugar del saber (2003), De Simón Rodríguez a Paulo Freire, Educación para la Integración Iberoamericana (2005); Adiós, Sarmiento. Educación pública, Iglesia y mercado (2017). Ha recibido numerosos premios y distinciones en el orden nacional e internacional. En el año 2017 fue distinguida con el título Doctora Honoris Causa por la Universidad Nacional de La Plata. 